\title{
FTY720 Regulates Bone Marrow Egress of Eosinophils and Modulates Late-Phase Skin Reaction in Mice
}

\author{
Kazunari Sugita, ${ }^{*}$ Kenji Kabashima, ${ }^{* \dagger}$ \\ Jun-ichi Sakabe, ${ }^{*}$ Ryutaro Yoshiki, ${ }^{*}$ \\ Hideaki Tanizaki, ${ }^{\dagger}$ and Yoshiki Tokura* \\ From the Department of Dermatology,* University of \\ Occupational and Environmental Health, Kitakyushu; and the \\ Department of Dermatology, ${ }^{\dagger}$ Kyoto University Graduate School \\ of Medicine, Kyoto, Japan
}

Eosinophilia in the blood and skin is frequently observed in patients with certain inflammatory skin diseases, such as atopic dermatitis. However, the mechanism underlying eosinophil circulation and the role of eosinophils in cutaneous immune responses remain unclear. In repeated hapten application-induced cutaneous responses in BALB/c mice, the administration of FTY720 before the last challenge decreased the number of skin-infiltrating eosinophils and reduced the late-phase reaction. A similar reduction of the late-phase reaction was observed by a sphingosine-1-phosphate G protein-coupled receptor (S1P1)-selective agonist, SEW2871. We monitored numerous alterations of eosinophils in the blood, spleen, bone marrow, and lymph nodes of interleukin- 5 transgenic mice, used as an eosinophilia model, following FTY720 administration. The number of circulating eosinophils was significantly decreased after treatment with FTY 720 , and eosinophils accumulated in the bone marrow. In addition, eosinophils expressed S1P1, S1P3, and S1P4 mRNAs, and their chemotactic response to S1P was abolished by FTY720 as well as by SEW2871. These findings suggest that FTY720 affects the number of eosinophils in both the blood and skin by inhibiting the egress of eosinophils from the bone marrow and thus downmodulating the late-phase reaction. (Am J Pathol 2010, 177:1881-1887; DOI: 10.2353/ajpath.2010.100119)

Eosinophils are thought to be involved in the pathogenesis of several skin disorders. For example, atopic dermatitis is characterized by an infiltrate of inflammatory cells, mainly consisting of $\mathrm{CD}^{+}$memory $\mathrm{T}$ cells, but distinct eosinophils constitute the inflammatory infiltrate in conjunction with $\mathrm{T}$ cells. ${ }^{1}$ The trafficking of eosinophils into inflammatory sites is regulated by a number of cytokines such as Th2 cell-derived interleukin (IL)-4, IL-5, and IL-13, chemokines such as regulated on activation normal T cell expressed and secreted/CCL5, and the eotaxins/CCL11 and adhesion molecules. ${ }^{2-6}$

Although accumulating studies have provided a significant insight on the association of cytokines and chemokines with cutaneous tissue eosinophilia, little information exists on eosinophil localization and functional role of cutaneous eosinophils. ${ }^{7}$ To study eosinophil kinetics and recruitment, IL-5 transgenic mice have been established and used as an eosinophilia model. ${ }^{8}$ In our preliminary study, when IL-5 transgenic mice were repeatedly sensitized to hapten and subsequently challenged with the same antigen, mice developed a late-phase cutaneous reaction and tissue eosinophilia, suggesting that eosinophils may be involved in the establishment of cutaneous late-phase reactions. Therefore, we speculated that the migration of eosinophils from lymphoid organs is a crucial step in the eosinophil localization to the skin, and this migration could be targeted to prevent the development of cutaneous diseases.

Sphingosine-1-phosphate (S1P) is a biologically active metabolite of plasma-membrane sphingolipids that is essential for immune-cell trafficking. ${ }^{9}$ The immune functions of S1P result from the engagement of five subtypes of $G$ protein-coupled receptors, S1P1-S1P5. Initial studies for evaluating the roles of S1P were performed with the compound FTY720. S1P1 expression on T cells determines the retention of naïve $T$ cells, but not memory $T$ cells, in

Supported in part by a grant-in-aid for Scientific Research from the Ministry of Education, Culture, Sports, Science, and Technology of Japan, the Ministry of Health, Labor, and Welfare of Japan.

Accepted for publication June 24, 2010.

Address reprint requests to Correspondence: Kazunari Sugita, M.D., Ph.D., and Kenji Kabashima, M.D., Ph.D., Department of Dermatology, University of Occupational and Environmental Health, 1-1 Iseigaoka, Yahatanishi-ku, Kitakyushu 807-8555, Japan. E-mail: k-sugita@med.uoehu.ac.jp and kaba@kuhp.kyoto-u.ac.jp. 
lymph nodes and their exit into the lymph in response to the S1P gradient, ${ }^{10,11}$ thereby modulating immune responses in vivo. ${ }^{12}$ Moreover, recent studies have identified that S1P is required for natural killer cell egress from lymph nodes and bone marrow. ${ }^{13}$ These findings raise a possibility that S1P and S1P receptors may function in the egress of lymphoid organs of eosinophils. However, the mechanism of migration of eosinophils from the lymphoid organs into the peripheries remains unelucidated.

In this study, we investigated the modulatory effect of FTY720 on eosinophil and late-phase reaction in mice. We evaluated the migration and trafficking of eosinophils between the systemic circulation and the skin. FTY720 inhibited eosinophil infiltration into the skin and attenuated the late-phase reaction of the skin. Our results propose a novel therapeutic approach of FTY720 on eosinophil localization and trafficking.

\section{Materials and Methods}

\section{Animals and Reagents}

Female C57BL/6 (B6), BALB/C, and New Zealand White (NZW) mice were purchased from Japan SLC (Hamamatsu, Japan). All experiments were conducted on 8-week-old mice. IL-5 transgenic mice were obtained from RIKEN BioResource Center (Tsukuba, Japan). These mice were maintained on a 12-hour light/dark cycle under specific pathogen-free conditions. All protocols were approved by the Institutional Animal Care and Use Committee of the University of Occupational and Environmental Health. 2,4,6-Trinitrochlorobenzene (TNCB) was obtained from Tokyo Kasei (Tokyo, Japan).

For treatment with FTY720 (Cayman Chemical, Ann Arbor, MI), mice were injected i.p. with $3.0 \mathrm{mg} / \mathrm{kg}$ FTY720 or with an equivalent volume of normal saline as a control at the indicated time points. Alternatively, mice were administered with S1P1 selective agonist SEW2871 (Calbiochem, San Diego, CA) before the final TNCB challenge by gavage because of its low solubility in aqueous solution. SEW2871 was dissolved in 10\% dimethyl sulfoxide and diluted with $25 \%$ Tween 20 as described previously. ${ }^{14}$ The dosage of $20 \mathrm{mg} / \mathrm{kg}$ was chosen based on the previous study showing a consistent lymphocytopenia up to 12 hours. ${ }^{14}$

\section{Flow Cytometry}

For flow cytometry, cells were plated at a density of $1 \times 10^{6}$ cells/well in 96-well U-bottomed plates (Falcon; BD Biosciences, San Jose, CA). Cells were stained for 20 minutes on ice with monoclonal antibodies (mAbs) in $25 \mu$ of PBS containing 2\% FCS, $1 \mathrm{mmol} / \mathrm{L}$ EDTA, and $0.1 \% \mathrm{NaN}_{3}$ and washed twice with $200 \mu$ l of this buffer. Data were collected on a FACSCanto system (BD Biosciences) and analyzed with FlowJo software (Tree Star, San Carlos, CA). The mAbs used were as follows: fluorescein isothiocyanate-conjugated anti-CD4 mAb, phosphatidylethanolamineconjugated anti-Siglec-F mAb, phosphatidylethanolamine-Cy5-conjugated anti-CD8 mAb, antigen-presenting cell-conjugated anti-B220 mAb (all from BD Biosciences), and phosphatidylethanolamine-Cy7-conjugated anti-Gr-1 mAb (eBioscience, San Diego, CA). Eosinophils were detected as Siglec- $\mathrm{F}^{+} \mathrm{Gr}-1^{\text {int+ }}$ population. ${ }^{15,16}$ The number of cells was determined by flow cytometry using Flow-Count Fluorospheres (Beckman Coulter, Fullerton, CA). ${ }^{17}$

\section{Inflammatory Skin Disease Model and Histology}

BALB/c mice were sensitized through the application of $50 \mu$ of $3 \%$ TNCB in $4: 1$ acetone/olive oil to their shaved abdomens on day 0 . They were challenged on both sides of each ear with $20 \mu \mathrm{l}$ of $0.2 \%$ TNCB in $1: 9$ acetone/olive oil on day 5 to evaluate contact hypersensitivity. To evaluate the inflammatory skin disease, mice sensitized in the same way 5 days before the first elicitation (day 0) were repeatedly challenged on the originally elicited ears with $20 \mu \mathrm{l}$ of $0.2 \%$ TNCB in $1: 9$ acetone/olive oil from days 8 to 29 at 3-day intervals as outlined in a previous report, with some modifications. ${ }^{18}$ On day 30 , they were then challenged on both sides of each ear with $20 \mu$ l of $0.2 \%$ TNCB in 1:9 acetone/olive oil. Ear thickness change was calculated as follows: (ear thickness after final challenge) (ear thickness before final challenge). FTY720 was applied by i.p. injection ( $3 \mathrm{mg} / \mathrm{kg}$ body weight) 24 hours before final TNCB challenge.

At 48 hours after the challenge with hapten, the ears of the mice were excised for histology and fixed in $10 \%$ formaldehyde. Five-micrometer-thick sections were prepared and stained with H\&E. Papanicolaou staining was used for eosinophil evaluation.

\section{5- (and 6-)Carboxyfluorescein Diacetate Succinimidyl Ester Cell Labeling and Tracking}

The axillary and inguinal lymph node cells, splenocytes, blood cells, and bone marrow cells from IL-5 transgenic mice were prepared, and single-cell suspensions were labeled with $6.5 \mu \mathrm{mol} / \mathrm{L}$ 5- (and 6-)carboxyfluorescein diacetate succinimidyl ester (CFSE) (Molecular Probes, Eugene, OR) as outlined in a previous report. ${ }^{6}$ Twentyfour hours before cell transfer, wild-type NZW mice were injected i.p. with $3 \mathrm{mg} / \mathrm{kg}$ FTY720 or normal saline. The cells resuspended in RPMI 1640 containing $0.2 \%$ FCS were injected i.v. in NZW mice $\left(2 \times 10^{7}\right.$ cells/mouse). Twelve hours after the cell transfer, the number of fluorescent cells in the bone marrow was enumerated by flow cytometry.

\section{Effect of IL-5 and FTY720 on Levels of Circulating and Bone Marrow Eosinophils}

B6 mice were administered with or without FTY720, and 24 hours later, the mice were injected i.v. with $100 \mu$ l of PBS containing IL-5 (500 pmol/kg) or PBS alone according to methods outlined in a previous study, with some modifications. ${ }^{19}$ Blood and bilateral femurs were taken 1 hour after i.v. injection of IL-5, and the number of eosinophils was determined by flow cytometry. 


\section{Cell Sorting and Quantitative PCR}

Eosinophils and CD4 ${ }^{+}$T cells from the bone marrow of IL-5 transgenic mice were isolated with a cell sorter (FACSAria II; BD, Franklin Lakes, NJ). The purity of the sorted cells was typically $>95 \%$. RNA was prepared from sorted cells with RNeasy (Qiagen, Valencia, CA), and cDNA was used for quantitative PCR. Murine S1P receptor expressions were quantified using TaqMan Gene Expression Assay (Applied Biosystems, Foster City, CA) in the ABI PRISM 7000 sequence detection system (Applied Biosystems) as follows: S1P1 (Assay ID: Mm00514644_m1), S1P2 (Assay ID: Mm01177794_m1), S1P3 (Assay ID: Mm00515669_m1), S1P4 (Assay ID: Mm00468695_s1), and S1P5 (Assay ID: Mm00474763_m1). As an endogenous reference for these PCR quantification studies, $\beta$-actin gene expression was measured using the TaqMan rodent $\beta$-actin control reagents (Applied Biosystems). The relative expression was calculated using the $2_{\mathrm{T}}{ }^{-} \Delta \Delta \mathrm{C}$ method. ${ }^{20}$ The expression of the target gene normalized to an endogenous, $\beta$-actin, reference and relative to a calibrator was given by the formula $2_{\mathrm{T}}{ }^{-} \Delta \Delta \mathrm{C}$. Gene expression in untreated mice was used as the calibrator to calculate $\Delta \Delta \mathrm{C}_{\mathrm{T}}$.

\section{Chemotaxis Assay}

Eosinophils in the bone marrow of IL-5 transgenic mice were tested for transmigration across uncoated 5- $\mu \mathrm{m}$ Transwell filters (Corning Costar, Corning, NY) to S1P (Sigma-Aldrich, St Louis, MO) or medium in the lower chamber over 3 hours. In some experiments, the cells were pretreated with FTY720 or SEW2871 described previously. ${ }^{21}$ The migrated cells were enumerated by flow cytometry. ${ }^{22}$ The medium used in this assay was RPMI
1640 with $0.5 \%$ fatty acid-free bovine serum albumin (Calbiochem, San Diego, CA).

\section{Statistical Analysis}

Data were analyzed using an unpaired two-tailed $t$-test. $P<0.05$ was considered to be significant.

\section{Results}

\section{Reduction of Eosinophil Infiltration into the Skin by FTY720 in a Murine Repeatedly Hapten-Challenged Dermatitis}

In a murine model of contact hypersensitivity, repeated application of a hapten such as TNCB to the same skin site in BALB/c mice results in a shift from a typical delayed-type hypersensitivity to an immediate type one. As a result, the late-phase reaction and eosinophil infiltration occur, usually 4 to 8 hours after the final challenge. ${ }^{18} \mathrm{We}$ used this model to evaluate the effect of FTY720 on tissue eosinophilia. Skin infiltration of eosinophils was inhibited by FTY720 treatment, but infiltration of lymphocytes was not changed (Figure 1A). This was further confirmed by Papanicolou staining, which showed reduced eosinophil infiltration by FTY720 (Figure 1B).

\section{Impairment of Cutaneous Late-Phase Reaction by FTY720 in IL-5 Transgenic Mice}

A previous study has demonstrated that the late-phase reaction caused by repeated painting with hapten is po-
A
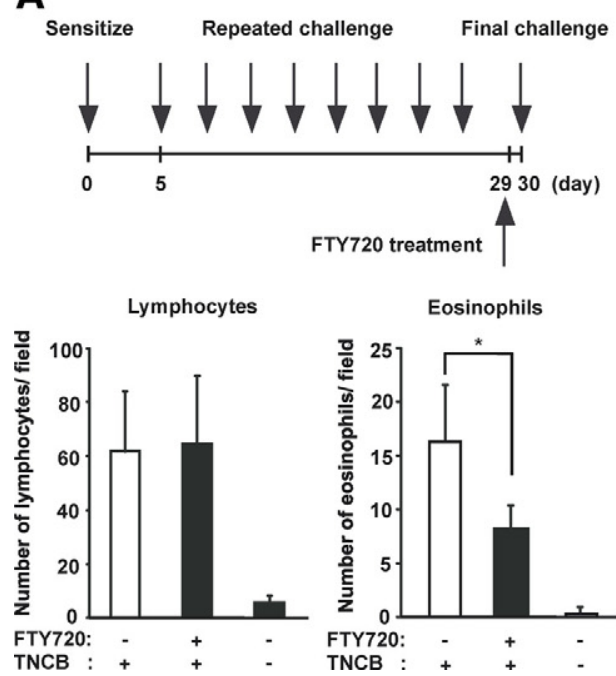

B

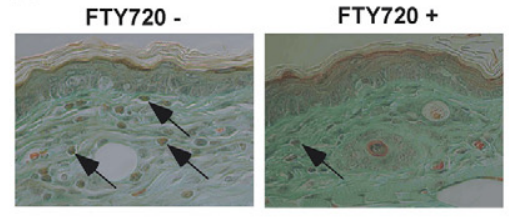

C

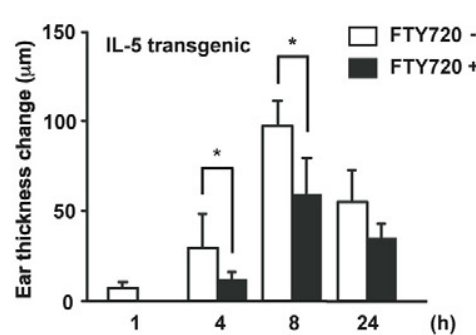

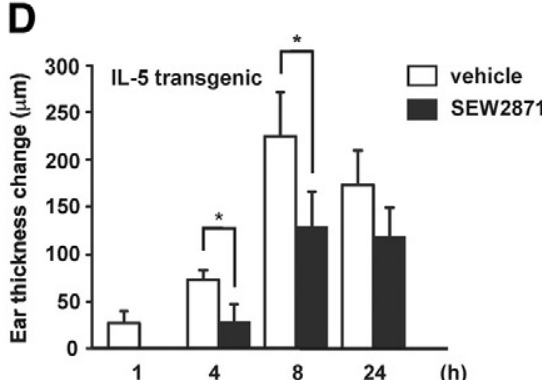

Figure 1. Effect of FTY720 on eosinophil accumulation in the skin. A: BALB/c mice were sensitized with TNCB on their shaved abdomens on day 0 . They were then challenged on both sides of each ear on day five. The mice were repeatedly challenged on the original sensitized ears with $0.2 \%$ TNCB from days 8 to 29 at 3-day intervals. At 48 hours after the final challenge, histological sections were prepared from the skin. The total numbers of lymphocytes and eosinophils were counted in five high-power fields. ${ }^{*} P<0.05$. B: Representative pictures of skin sections from control and FTY 720 -treated mice challenged with TNCB. Data are from two independent experiments. Arrows indicate eosinophils. C: The ear swelling responses were measured before and at $1,4,8$, and 24 hours after the final challenge. Data are from three independent experiments. ${ }^{*} P<0.05$. D: Similar results were obtained when mice were treated with SEW 2871 . Data are from two independent experiments. ${ }^{*} P<0.05$. 
tentiated in IL-5 transgenic mice. ${ }^{8}$ This enhancement may be related to tissue eosinophilia in the skin. Therefore, we investigated the significance of FTY720 on cutaneous late-phase reaction in vivo using IL-5 transgenic mice. IL-5 transgenic mice were sensitized with TNCB on day 0 and elicited with TNCB on the abdomen from days 5-29 at 3-day intervals. On day 30, they were challenged on both sides of each ear.

The treatment of mice with FTY720 12 hours before the challenge yielded reduced ear swelling responses at 4 and 8 hours after challenge (Figure $1 C$ ). Because the skin infiltration of eosinophils was suppressed by FTY720, the data were interpreted to result from the direct effect of FTY720 on eosinophils. Similar findings were observed when SEW2871 were administered (Figure 1D).

\section{Numerical Alterations of Eosinophils after FTY720 Treatment}

To clarify the mechanisms underlying the FTY720-induced reduction of skin eosinophils, we first evaluated the kinetics of eosinophils in the blood. It is known that FTY720 inhibits T cell egress from the secondary lymph nodes and decreases circulating T cells. ${ }^{23-26}$ We examined the time course of decrease in the circulating Siglec$\mathrm{F}^{+} \mathrm{Gr}-1^{\text {int+ }}$ eosinophils after treatment of IL-5 transgenic mice with FTY720. The blood was drawn by intraocular venipuncture before and 1, 3, 5, and 7 days after FTY720 administration. The number of eosinophils was decreased markedly 1 to 5 days after FTY720 treatment and returned to the baseline level on day 7 (Figure 2). A similar reduction of circulating eosinophils was observed 6 hours after SEW2871 administration: vehicle, $13.6 \pm$ $2.0 \times 10 / \mathrm{mm}^{3}$; and SEW2871 treatment, $2.2 \pm 0.1 \times$ $10 / \mathrm{mm}^{3}(P<0.001$, mean \pm SD of three mice). However, the decreased number of eosinophils in the blood returned to the normal range 48 hours after treatment with SEW2871 $\left(12.5 \pm 2.1 \times 10 / \mathrm{mm}^{3}\right)$.

Because blood eosinophils were decreased by FTY720, we examined the localization of eosinophils after treatment with FTY720. At 24 hours after administration of

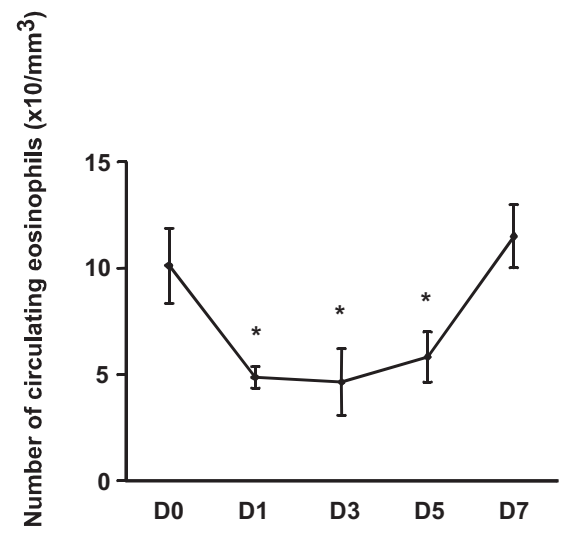

Figure 2. Numerical alterations of eosinophils in the peripheral blood Figure 2. Numerical alterations of eosinophils in the peripheral blood
following FTY720 administration. FTY 720 was administered to IL-5 transgenic mice, and peripheral blood samples were periodically collected. Data are expressed as the mean $\pm \mathrm{SD}$. Data are from three independent experiments. ${ }^{*} P<0.05$
A

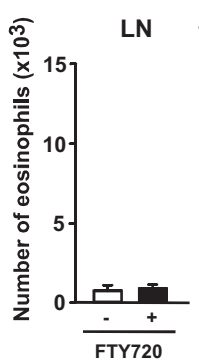

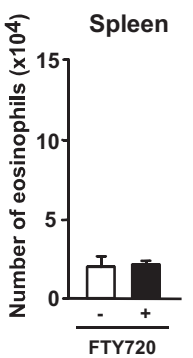

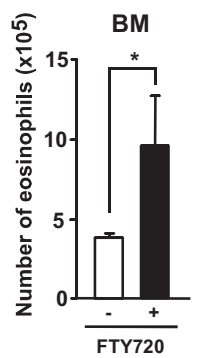

B

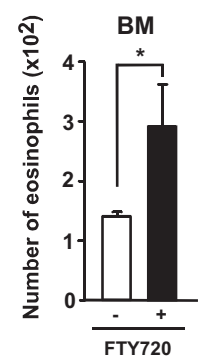

Figure 3. Accelerated accumulation of eosinophils by FTY 720 in the bone marrow. A: FTY 720 was administered to IL-5 transgenic mice. At 24 hours, lymph node cells, splenocytes, and bone marrow cells were harvested, and single-cell suspensions were analyzed by FACS for the presence of eosinophils. The homing of eosinophils to the bone marrow in the IL- 5 transgenic mice was higher than that in the control mice. B: CFSE-labeled cells from IL-5 transgenic mice were adaptively transferred into control or FTY720-treated wild-type NZW mice. After 12 hours, the mice were killed, and eosinophils were harvested. Single-cell suspensions were analyzed by flow cytometry for the presence of CSFE-positive donor eosinophils. Error bars indicate the mean \pm SEM from at least four mice per group. Data are from three independent experiments. ${ }^{*} P<0.05$.

FTY720, the levels of eosinophils homing to the lymph nodes and spleen remained unchanged, but the number of eosinophils in the bone marrow increased (Figure 3A).

To examine the involvement of $\mathrm{S} 1 \mathrm{P}$ in the regulation of eosinophil trafficking, CFSE-labeled cells collected from IL-5 transgenic mice were adoptively transferred to wildtype naïve NZW mice treated with or without FTY720. Treatment of the mice with FTY720 increased the number of CFSE-labeled eosinophils in the bone marrow (Figure $3 B$ ). These results suggest that FTY720 regulates the localization of eosinophils by inhibiting the egress of eosinophils from the bone marrow.

\section{Inhibition of IL-5-Induced Eosinophilia by FTY720 Treatment}

It is known that i.v. administration of IL-5 induces a rapid and sustained increase in the number of circulating eosinophils by mobilization from the bone marrow in B6 mice. ${ }^{19}$ In confirmation of this notion, i.v. administration of $500 \mathrm{pmol} / \mathrm{kg} \mathrm{IL}-5$ induced pronounced blood eosinophilia in B6 mice (Figure 4, A and B). This increase was attenuated by treatment with FTY720 (Figure 4, A and B). In another study, B6 mice were pretreated with or without FTY720, and IL-5 was injected i.v. 24 hours later. The number of eosinophils was significantly increased in the bone marrow of FTY720-treated mice 12 hours after injection (Figure 4C). Thus, FTY720 depresses the recruitment of eosinophils from the bone marrow pool to the blood.

\section{S1P Receptor mRNA Expressions in Eosinophils}

To measure S1P receptor abundance in eosinophils, bone marrow cells were prepared from IL-5 transgenic mice, and Siglec- $\mathrm{F}^{+} \mathrm{Gr}-1^{\text {int }}{ }^{+}$eosinophils and $\mathrm{CD} 4^{+} \mathrm{T}$ cells were purified by a cell sorter. We evaluated the expression levels of S1P receptor mRNAs by quantitative PCR. S1P1, S1P3, and S1P4 mRNAs were expressed in eosin- 
A $\mathrm{CD}^{-} \mathrm{CD} 8^{-} \mathrm{B} 220^{-}$
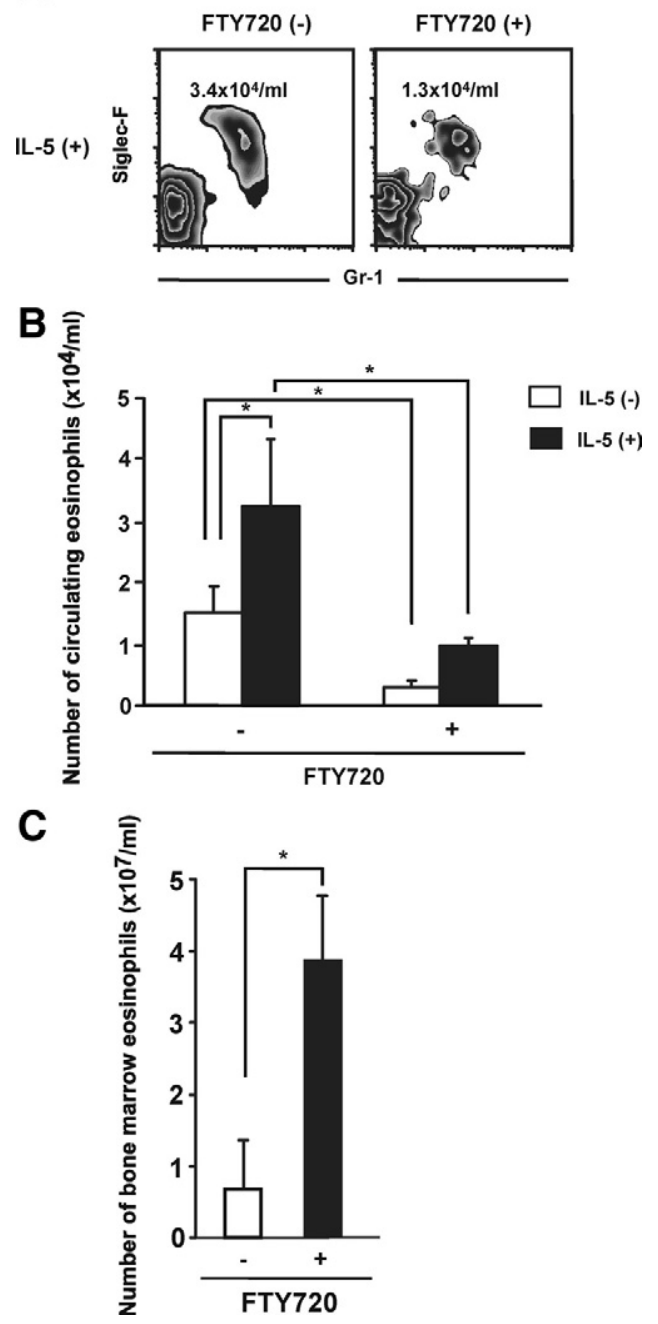

Figure 4. Effect of FTY720 after i.v. administration of IL-5 on circulating and bone marrow eosinophils. A-C: FTY720 was i.p. injected into B6 mice 24 hours before IL-5 injection. Mice were injected with IL-5 or vehicle alone. A and B: Circulating eosinophil numbers were determined 1 hour after injection of IL-5. C: After 12 hours, bone marrow samples were harvested, and single cell suspensions were analyzed by flow cytometry for the presence of eosinophils. Error bars indicate the mean \pm SEM from at least four mice per group. Data are from three independent experiments. ${ }^{*} P<0.05$.

ophils, and their levels were higher than those in keratinocyte cell line PAM212. In contrast, S1P1 mRNA level was higher in T cells than eosinophils, and S1P4 level was comparable in T cells and eosinophils (Figure 5).

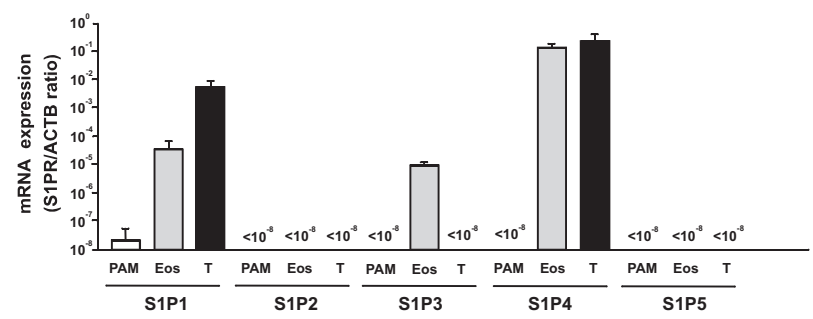

Figure 5. Quantitative PCR analysis of S1P receptor mRNAs from eosinophils. Bone marrow cells from IL-5 transgenic mice were sorted into Siglec$\mathrm{F}^{+} \mathrm{Gr}-1^{\text {int }}{ }^{+}$eosinophils and $\mathrm{CD}^{+}{ }^{+} \mathrm{T}$ cells. The amounts of S1P receptor mRNA were expressed as relative amounts of S1P receptor mRNA normalized to $\beta$-actin. Data are from two independent experiments.

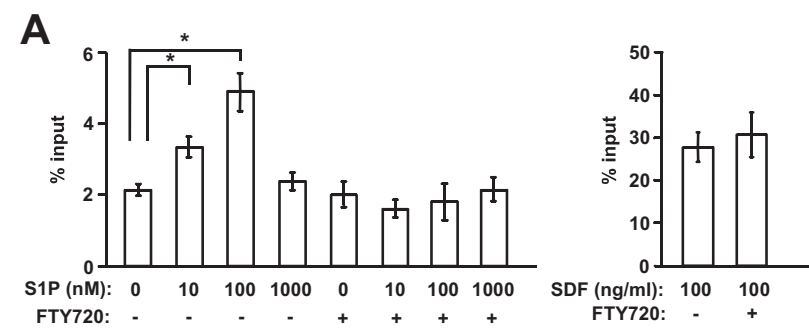

B

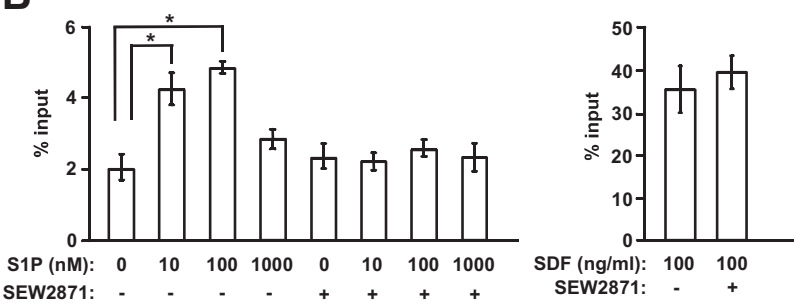

Figure 6. Chemotactic response of eosinophils to S1P. A: Bone marrow cells were prepared from IL-5 transgenic mice with or without FTY720. B: In some experiments, bone marrow cells were pretreated with $1000 \mathrm{nmol} / \mathrm{L}$ SEW2871. Chemotactic activities of eosinophils to stromal cell-derived factor 1 (SDF) were unaffected by treatment with either FTY720 or SEW2871. A and B: Input cells and cells that migrated to the lower well of the Transwell chamber in the absence of chemokine or in response to S1P were analyzed by flow cytometry to detect eosinophils. Bars represent means of triplicated Transwells, and data are from three independent experiments. ${ }^{*} P<0.05$

\section{Eosinophil Chemotactic Response to S1P}

FTY720 inhibits T cell emigration through inhibition of S1PS1P1 signaling. ${ }^{27}$ Therefore, as readout of S1P1 function on eosinophils, we evaluated the chemotactic response to $\mathrm{S} 1 \mathrm{P}$. The cells were isolated from the bone marrow of IL-5 transgenic mice that were treated with FTY720. Chemotaxis assay using transwells showed that naive $T$ cells had a good chemotactic response to S1P, which was ablated by FTY720 as reported previously. ${ }^{12,21}$ Eosinophils had a significant chemotactic response to S1P but lost the ability to respond to S1P when mice were pretreated with FTY720 (Figure 6A). Similar inhibition of eosinophil chemotaxis to S1P was observed with SEW2871 (Figure 6B). The chemotactic response to stromal-cell derived factor-1 was not affected by the administration of FTY720 or SEW2871 (Figure 6). These data suggest that the migration of eosinophils toward S1P is highly dependent on S1P1.

\section{Discussion}

Our study demonstrated that the administration of FTY720 before the final challenge decreased the number of skin-infiltrating eosinophils and the cutaneous latephase reaction. The egress of eosinophils from the bone marrow was inhibited by FTY720 treatment. This may subsequently lead to attenuate the accumulation of eosinophils in the skin.

By acting as an agonist for S1P receptors and thereby inhibiting lymphocyte egress from lymphoid organs, it has been reported that FTY720 shows a strong therapeutic potential for preventing the rejection of transplanted organs and for treating autoimmune diseases, such as autoimmune encephalomyelitis and systemic lupus ery- 
thematosus. ${ }^{28}$ In fact, some of these possible therapeutic uses are currently being clinically evaluated. ${ }^{29}$ We have demonstrated that FTY720 impairs naive T cell circulation and markedly disrupts the acquired skin Th1 type immune response. ${ }^{12}$ Consequently, FTY720 may have the potential to prevent the onset of disease rather than to treat memory $\mathrm{T}$ cell-mediated acquired skin immune responses. $^{12}$

It remains unclear from this study how S1P-S1P receptor signaling participate in the infiltration of eosinophils from the blood to the skin. Several possible mechanisms for the regulation of eosinophil trafficking into the skin can be proposed. First, FTY720 might directly inhibit the migration of eosinophil toward the skin constituents, because eosinophils express S1P1, and S1P is induced at the epidermis of the skin. ${ }^{30,31}$ This idea is supported by the results of our chemotaxis assay, which showed a direct suppressive effect of FTY720 on eosinophil migration toward S1P. Second, a significant reduction of the eosinophilic inflammation in the skin was observed with FTY720, suggesting that the decrease in circulating eosinophils may affect the eosinophil recruitment process. Indeed, FTY720 enhanced the accumulation of adaptively transferred eosinophils in the bone marrow, indicating that eosinophil retention in this organ is also regulated by S1P.

Eosinophils play a key role in the development of cutaneous late-phase reactions. Circulating eosinophils are complemented from the bone marrow in an S1P-S1P1dependent manner. Previous studies have reported that a decrease in S1P release by sphingosine kinase inhibitors controls a mouse asthmatic model. The authors demonstrated that inhaled delivery of sphingosine kinase inhibitors prevented eosinophilic inflammations and goblet hyperplasia induced by OVA administration. ${ }^{32}$ Their observation and our finding provide a possibility that FTY720 may be a candidate of treatment modalities for eosinophilic cutaneous inflammations, such as atopic dermatitis, hypereosinophilic syndrome, and ChurgStrauss syndrome. ${ }^{33,34}$

There have been few studies on S1P receptor expressions on murine eosinophils and the functional role of S1P1 on eosinophils in vivo. ${ }^{9,35}$ Our current study indicated that S1P1 expression was lower in eosinophils than T cells. Therefore, the S1P-S1P1 dependency of eosinophils may be lower than that of $T$ cells, which might explain the less inhibitory effects of FTY720 on eosinophils in the blood. In the model where mice were repeatedly challenged with a hapten, FTY720 also reduced the number of skin-infiltrating eosinophils but not $T$ cells. Consequently, FTY720 attenuated the late-phase reaction along with a reduction of eosinophil infiltration. S1P1 is known to be required for normal B cell development. ${ }^{36}$ S1P4 signaling in migratory response of murine T cells toward S1P remains controversial. ${ }^{37,38}$ In contrast to S1P1 and S1P4 in B and T cells, the roles of these receptors for eosinophils remain unclear. In human, the eosinophil recruitment process has been reported to depend on not only S1P1 but also S1P2 and S1P3 mRNA levels. ${ }^{35}$ Although we cannot rule out a possibility that the localization of eosinophils is related to S1P3, our in vivo and in vitro studies using SEW2871 and FTY720 strongly suggest that S1P1 is involved in bone marrow egress and peripheral tissue localization of eosinophils.

\section{References}

1. Leung DY, Bieber T: Atopic dermatitis. Lancet $2003,361: 151-160$

2. Sher A, Coffman RL, Hieny S, Cheever AW: Ablation of eosinophil and IgE responses with anti-IL-5 or anti-IL-4 antibodies fails to affect immunity against Schistosoma mansoni in the mouse. J Immunol 1990, 145:3911-3916

3. Moser R, Fehr J, Bruijnzeel PL: IL-4 controls the selective endothelium-driven transmigration of eosinophils from allergic individuals. J Immunol 1992, 149:1432-1438

4. Horie S, Okubo Y, Hossain M, Sato E, Nomura H, Koyama S, Suzuk J, Isobe M, Sekiguchi M: Interleukin-13 but not interleukin-4 prolongs eosinophil survival and induces eosinophil chemotaxis. Intern Med 1997, 36:179-185

5. Hogan SP, Rosenberg HF, Mogbel R, Phipps S, Foster PS, Lacy P, Kay $A B$, Rothenberg ME: Eosinophils: biological properties and role in health and disease. Clin Exp Allergy 2008, 38:709-750

6. Mori T, Kabashima K, Yoshiki R, Sugita K, Shiraishi N, Onoue A, Kuroda E, Kobayashi M, Yamashita U, Tokura Y: Cutaneous hypersensitivities to hapten are controlled by IFN- $\gamma$-upregulated keratinocyte Th1 chemokines and IFN- $\gamma$-downregulated langerhans cell Th2 chemokines. J Invest Dermatol 2008, 128:1719-1727

7. Homey B, Steinhoff M, Ruzicka T, Leung DY: Cytokines and chemokines orchestrate atopic skin inflammation. J Allergy Clin Immunol 2006, 118:178-189

8. Nagai H, Ueda $Y$, Tanaka H, Hirano $Y$, Nakamura N, Inagaki $N$, Takatsu K, Kawada K: Effect of overproduction of interleukin 5 on dinitrofluorobenzene-induced allergic cutaneous response in mice. J Pharmacol Exp Ther 1999, 288:43-50

9. Rivera J, Proia RL, Olivera A: The alliance of sphingosine-1-phosphate and its receptors in immunity. Nat Rev Immunol 2008, 8:753-763

10. Lo CG, Xu Y, Proia RL, Cyster JG: Cyclical modulation of sphingosine-1-phosphate receptor 1 surface expression during lymphocyte recirculation and relationship to lymphoid organ transit. J Exp Med 2005, 201:291-301

11. Pappu R, Schwab SR, Cornelissen I, Pereira JP, Regard JB, Xu Y, Camerer E, Zheng YW, Huang Y, Cyster JG, Coughlin SR: Promotion of lymphocyte egress into blood and lymph by distinct sources of sphingosine-1-phosphate. Science 2007, 316:295-298

12. Nakashima D, Kabashima K, Sakabe J, Sugita K, Kobayashi T, Yoshiki R, Tokura Y: Impaired initiation of contact hypersensitivity by FTY720. J Invest Dermatol 2008, 128:2833-2841

13. Jenne CN, Enders A, Rivera R, Watson SR, Bankovich AJ, Pereira JP, Xu Y, Roots CM, Beilke JN, Banerjee A, Reiner SL, Miller SA, Weinmann AS, Goodnow CC, Lanier LL, Cyster JG, Chun J: T-bet-dependent S1P5 expression in NK cells promotes egress from lymph nodes and bone marrow. J Exp Med 2009, 206:2469-2481

14. Sanna MG, Liao J, Jo E, Alfonso C, Ahn MY, Peterson MS, Webb B, Lefebvre S, Chun J, Gray N, Rosen H: Sphingosine 1-phosphate (S1P) receptor subtypes S1P1 and S1P3, respectively, regulate lymphocyte recirculation and heart rate. J Biol Chem 2004, 279: 13839-13848

15. Voehringer D, Shinkai K, Locksley RM: Type 2 immunity reflects orchestrated recruitment of cells committed to IL-4 production. Immunity 2004, 20:267-277

16. Tateno $H$, Crocker PR, Paulson JC: Mouse Siglec-F and human Siglec-8 are functionally convergent paralogs that are selectively expressed on eosinophils and recognize 6'-sulfo-sialyl Lewis $\mathrm{X}$ as a preferred glycan ligand. Glycobiology 2005, 15:1125-1135

17. Sugita K, Kabashima K, Yoshiki R, Ikenouchi-Sugita A, Tsutsui M, Nakamura J, Yanagihara N, Tokura Y: Inducible nitric oxide synthase downmodulates contact hypersensitivity by suppressing dendritic cell migration and survival. J Invest Dermatol 2010, 130:464-471

18. Kitagaki H, Ono N, Hayakawa K, Kitazawa T, Watanabe K, Shiohara $\mathrm{T}$ : Repeated elicitation of contact hypersensitivity induces a shift in cutaneous cytokine milieu from a Thelper cell type 1 to a T helper cell type 2 profile. J Immunol 1997, 159:2484-2491

19. Mould AW, Matthaei KI, Young IG, Foster PS: Relationship between 
interleukin-5 and eotaxin in regulating blood and tissue eosinophilia in mice. J Clin Invest 1997, 99:1064-1071

20. Livak KJ, Schmittgen TD: Analysis of relative gene expression data using real-time quantitative PCR and the $2(-\Delta \Delta \mathrm{C}(\mathrm{T}))$ method. Methods 2001, 25:402-408

21. Maeda Y, Matsuyuki H, Shimano K, Kataoka H, Sugahara K, Chiba K: Migration of CD4 T cells and dendritic cells toward sphingosine 1-phosphate (S1P) is mediated by different receptor subtypes: S1P regulates the functions of murine mature dendritic cells via S1P receptor type 3. J Immunol 2007, 178:3437-3446

22. Kabashima K, Haynes NM, Xu Y, Nutt SL, Allende ML, Proia RL, Cyster JG: Plasma cell S1P1 expression determines secondary lymphoid organ retention versus bone marrow tropism. J Exp Med 2006, 203:2683-2690

23. Lien YH, Yong KC, Cho C, Igarashi S, Lai LW: S1P(1)-selective agonist. SEW2871, ameliorates ischemic acute renal failure. Kidney Int 2006, 69:1601-1608

24. Chiba K, Yanagawa Y, Masubuchi Y, Kataoka H, Kawaguchi T, Ohtsuki M, Hoshino Y: FTY720, a novel immunosuppressant, induces sequestration of circulating mature lymphocytes by acceleration of lymphocyte homing in rats. I FTY720 selectively decreases the number of circulating mature lymphocytes by acceleration of lymphocyte homing. J Immunol 1998, 160:5037-5044

25. Sallusto F, Lenig D, Forster R, Lipp M, Lanzavecchia A: Two subsets of memory T lymphocytes with distinct homing potentials and effector functions. Nature 1999, 401:708-712

26. Matloubian M, Lo CG, Cinamon G, Lesneski MJ, Xu Y, Brinkmann V, Allende ML, Proia RL, Cyster JG: Lymphocyte egress from thymus and peripheral lymphoid organs is dependent on S1P receptor 1 . Nature 2004, 427:355-360

27. Sawicka E, Zuany-Amorim C, Manlius C, Trifilieff A, Brinkmann V, Kemeny DM, Walker C: Inhibition of Th1- and Th2-mediated airway inflammation by the sphingosine 1-phosphate receptor agonist FTY720. J Immunol 2003, 171:6206-6214

28. Okazaki $H$, Hirata D, Kamimura $T$, Sato $H$, Iwamoto M, Yoshio $T$, Masuyama J, Fujimura A, Kobayashi E, Kano S, Minota S: Effects of
FTY720 in MRL-Ipr/Ipr mice: therapeutic potential in systemic lupus erythematosus. J Rheumatol 2002, 29:707-716

29. Brinkmann V: FTY720 (fingolimod) in multiple sclerosis: therapeutic effects in the immune and the central nervous system. Br J Pharmacol 2009, 158:1173-1182

30. Kurashima Y, Kunisawa J, Higuchi M, Gohda M, Ishikawa I, Takayama N, Shimizu M, Kiyono H: Sphingosine 1-phosphate-mediated trafficking of pathogenic Th2 and mast cells for the control of food allergy. J Immunol 2007, 179:1577-1585

31. Hong JH, Youm JK, Kwon MJ, Park BD, Lee YM, Lee SI, Shin DM, Lee $\mathrm{SH}$ : K6PC-5, a direct activator of sphingosine kinase 1, promotes epidermal differentiation through intracellular $\mathrm{Ca}^{2+}$ signaling. J Invest Dermatol 2008, 128:2166-2178

32. Nishiuma T, Nishimura Y, Okada T, Kuramoto E, Kotani Y, Jahangeer S, Nakamura S: Inhalation of sphingosine kinase inhibitor attenuates airway inflammation in asthmatic mouse model. Am J Physiol Lung Cell Mol Physiol 2008, 294:L1085-L1093

33. Roufosse FE, Goldman M, Cogan E: Hypereosinophilic syndromes. Orphanet J Rare Dis 2007, 2:37

34. Shimauchi T, Kabashima K, Tokura Y: Solar urticaria as a manifestation of Churg-Strauss syndrome. Clin Exp Dermatol 2007, 32:209-210

35. Roviezzo F, Del Galdo F, Abbate G, Bucci M, D'Agostino B, Antunes E, De Dominicis G, Parente L, Rossi F, Cirino G, De Palma R: Human eosinophil chemotaxis and selective in vivo recruitment by sphingosine 1-phosphate. Proc Natl Acad Sci USA 2004, 101:11170-11175

36. Allende ML, Tuymetova G, Lee BG, Bonifacino E, Wu YP, Proia RL S1P1 receptor directs the release of immature $B$ cells from bone marrow into blood. J Exp Med 2010, 207:1113-1124

37. Matsuyuki H, Maeda Y, Yano K, Sugahara K, Chiba K, Kohno T, Igarashi Y: Involvement of sphingosine 1-phosphate (S1P) receptor type 1 and type 4 in migratory response of mouse T cells toward S1P. Cell Mol Immunol 2006, 3:429-437

38. Graeler M, Shankar G, Goetzl EJ: Cutting edge: suppression of T cell chemotaxis by sphingosine 1-phosphate. J Immunol 2002, 169: 4084-4087 